\title{
O conhecimento tático produto de métodos de ensino combinados e aplicados em sequências inversas no voleibol
}

CDD. 20.ed. 796.073

796.325

\author{
Cláudio Olivio Vilela LIMA*/***** \\ Cristino J ulio Alves da Silva MATIAS* \\ Pablo Juan GRECO*
}

*Centro de Estudos
de Cognição e Ação,
Escola de Educação
Física, Fisioterapia e
Terapia Ocupacional,
Universidade Federal
de Minas Gerais.
**Centro Universitá-
rio Metodista Izabela
Hendrix.
***Núcleo de Integra-
ção das Ciências do
Esporte, Minas Tênis
Clube.

0 objetivo desta pesquisa foi investigar as diferenças entre os métodos de ensino situacional e tradicional no desenvolvimento do conhecimento tático declarativo e processual nas sessões de treinamento de voleibol, bem como observar a influência da ordem de aplicação desses métodos no conhecimento tático. A amostra foi composta por 36 estudantes (sexo masculino - faixa etária de 12 a 14 anos), sendo 22 destes inscritos nas equipes escolares de voleibol e 14 não praticantes de voleibol (grupo controle). Um grupo iniciou o processo de ensino-aprendizagem-treinamento pelo método situacional (GST) e outro pelo método tradicional (GTS). Ao final de 15 sessões o método foi invertido e realizado o mesmo número de sessões. Para confirmar a execução do método de ensino foi empregada a observação e categorização dos treinos (STEFANELLO, 1999). Para a avaliação do conhecimento processual foi utilizado o teste KORA (MEMMERT, 2002), no parâmetro tático reconhecer espaços. Já no declarativo usou-se o teste de Conhecimento Tático em Situação de Ataque de Rede (PAULA, 2000). Os três grupos no pré-teste demonstram estar inicialmente no mesmo patamar de conhecimento tático declarativo e processual. No GST, ao se aplicar o método situacional (referente às 15 sessões iniciais), não houve diferença significativa no conhecimento tático declarativo, mas houve no processual convergente e divergente. Já no GTS, ao empregar o método tradicional, não se confirmou o desenvolvimento de nenhum dos conhecimentos táticos. Ao efetuar a inversão do método de ensino, no GST (30 sessões na sequência situacional-tradicional) foi apurada melhoria significativa de ambos os conhecimentos táticos processuais. Entretanto, o mesmo não ocorreu no GTS na sequência tradicional-situacional. Os resultados indicam que a sequência de treinamentos referentes ao GST proporcionou melhoras relevantes na inteligência e na criatividade tática dos jogadores.

UnItermos: Cognição e ação; Ensino-aprendizagem-treinamento; Jogos esportivos coletivos.

\section{Introdução}

No início do século XIII iniciou-se o processo de regulamentação dos jogos, que posteriormente transformam-se em esportes. Atualmente, um conjunto de esportes recebe a denominação de Jogos Esportivos Coletivos, como é o caso do basquetebol, futebol, futsal, handebol, "hockey", entre outros. A competição esportiva de forma estruturada ocorreu com o ressurgimento dos Jogos Olímpicos, em 1896, com a disputa de modalidades individuais (atletismo, natação, esgrima, lutas, entre outras). Já em Paris, nos Jogos Olímpicos de 1900, os Jogos Esportivos Coletivos passaram a integrar o programa das Olimpíadas, com a inclusão do críquete, futebol, pólo e "rugby" (De Rose Junior \& Silva, 2006).
Entre os fatores diferenciadores do voleibol, em relação às outras modalidades dos Jogos Esportivos Coletivos, destaca-se o obrigatório rodízio de posiçóes na quadra. Tal rodízio sempre forma seis diferentes composições do time na quadra, as quais se relacionam com seis diferentes composiçôes do adversário (MATIAS \& GRECO, 2009). Logo, o processo decisório do jogador necessita ser elaborado em concomitância com o contexto de cada uma das composições de uma equipe em relação à outra. Estas relações táticas, entre a própria equipe e o adversário, possuem na imprevisibilidade, na aleatoriedade e na variabilidade do encadeamento das açōes um dificultador no processo de tomada de decisão do jogador (GARGANTA, 2002, 2006). 
O manejo da bola é outra dificuldade do voleibol, pois tal ato ocorre apenas no saque. Ao efetuar o saque o jogador pode segurar a bola na preparação desta ação. Já nas outras açōes o jogador fica limitado à realização de um único toque na bola, além de estar sob pressão de tempo para efetuar uma decisão com eficácia e eficiência (Mesquita, Marques \& MaiA, 2001; Rizola, 2003).

Para que o jogador de voleibol tenha um comportamento inteligente durante uma partida é preciso que haja compreensão sobre "o que fazer", "quando fazer" e "como fazer" (Giacomini \& Greco, 2008; Greco \& Chagas, 1992; Matias, 2009; Matias \& Greco, 2009, 2010; Morales \& Greco, 2007; Moralez, Azevedo, Maciel, Barcelos, Áreas Neto \& Silva, 2009a; Oliveira, Beltrāo \& Silva, 2003; Queiroga, 2005; Vilhena \& Greco, 2009). De acordo com GRECO (2006a, 2006b) o conhecimento propicia a compreensão do jogo e a realização do processo decisório. Em tal processo, por meio da percepção o jogador apura os sinais relevantes da partida, mediante alternância do foco da atenção, e assim efetua uma tomada de decisão inteligente e/ou criativa. Logo, a cognição torna-se fundamental para um rendimento satisfatório nos Jogos Esportivos Coletivos (Araújo, 2009; Greco, 2006a; Greco, 2006b; Matias \& Greco, 2010; Mesquita, 2005).

As Ciências do Esporte, com aporte da Psicologia Cognitiva, descreve que são dois os tipos de conhecimento: o declarativo e o processual (EYSENCK \& KeAne, 1994; HenKe, 2010; Sternberg, 2008). O declarativo propicia ao jogador verbalizar a respeito das próprias decisōes, refere-se ao "o que fazer". O processual permite ao jogador saber "como fazer" e "quando fazer", seleciona-se o gesto técnico mais adequado, de forma automática e sem aparente controle consciente. Assim sendo, por meio da ação tático-técnica, o jogador soluciona as diferentes tarefas-problemas da competição (Greco, 2006a, 2006b; Matias \& Greco, 2010). Ao contrário do conhecimento declarativo que pode ser explanado, o conhecimento processual, geralmente, não pode ser formulado explicitamente (EYSENCK \& KEANE, 1994). O conhecimento processual é um processo mais complexo em relação ao declarativo. Isto, uma vez que a efetuação motora de uma habilidade técnica ocorre a partir da elaboração mental da tomada de decisão (MCPHERSON, 1999). A procedimentalização complementa as definições destes conhecimentos. $\mathrm{Na}$ procedimentalização os conhecimentos representados na forma declarativa vão sendo compilados em regras ou procedimento (ANDERSON, 1995a, 1995b; Henke, 2010; Sternberg, 2008).
Há no desporto coletivo jogadores altamente habilidosos que, no entanto, não conseguem na interação da própria equipe com o adversário a produção de decisōes táticas inteligentes e/ou criativas, pois não sabem "como" e "quando" usar a técnica de forma eficaz (Turner \& MARTINeK, 1995). Então, apresenta-se uma falha, seja na transferência do nível de conhecimento declarativo para o processual ou no apropriado uso destes conhecimentos, ou seja, há um problema tático decorrente da não compreensão do jogo (GiaCOMINI \& GRECO, 2008). Investigações científicas no desporto revelam que os jogadores peritos possuem um maior e mais estruturado conhecimento tático declarativo e processual (BANKS \& MilLWARD, 2007; French, Nevett, Spurgeon, Graham, Rink \& MCPHerson, 1996; MCPherson, 1994; RinK, FrenCH \& TJeerdsma, 1996; Williams, 2002; Williams \& Davids, 1995; ZoudjI, Thon \& Debu, 2010).

A operacionalização do conhecimento do jogador ocorre por meio do pensamento divergente e convergente (GRECO, 2006a, 2006b). O pensamento convergente aplica-se quando o jogador procura resolver um problema com uma seqüência definida e hierárquica de alternativas, quando é evidente a solução mais adequada. Já o pensamento divergente é empregado em situaçóes que não apresentam uma clara hierarquia de ações, há várias soluções diferentes e possíveis. $\mathrm{O}$ pensamento convergente está ligado à inteligência do jogador e o pensamento divergente ligado à criatividade. Estas duas formas de pensamento não são excludentes, pelo contrário, relacionam-se entre si e uma oferece subsídios à outra (STERNBERG, 2008).

O método de ensino, no processo de ensinoaprendizagem-treinamento dos Jogos Esportivos Coletivos, deve ser formulado cuidadosamente, o que solicita do professor/treinador o conhecimento das diferentes alternativas metodológicas (COSTA \& Nascimento, 2004; MesQuita, 2005). Dentre estas destacam-se os métodos tradicionais e situacionais.

No método tradicional é enfatizada a capacidade técnica. São empregados exercícios cuja repetição é valorizada por meio do princípio de desenvolvimento dos fundamentos técnicos individuais e/ou de combinações destes fundamentos. $\mathrm{O}$ modelo biomecânico de execução do movimento esportivo torna-se o padrão de correção e todas as outras formas são consideradas inequívocas ou incompletas. As técnicas do jogo se apresentam com finalidades em si mesmas, sem articulação com o jogo praticado pelos alunos e/ou atleta, com geração de ações mecanizadas no âmago do jogo. O jogo tem o modelo adulto como indicativo e é efetuado ao final da sessão 
de treinamento. Em decorrência do referencial no modelo adulto não há diferenciação tático-técnica entre os praticantes. Desta forma, os indivíduos é que se adaptam as regras do jogo e não o contrário (Costa \& NASCIMENTO, 2004; DAOLIO, 2002; GARGANTA, 1998a, 1998b; GraÇA \& MESQUiTA, 2002).

O método situacional desenvolve a capacidade tática, mediante a percepção das situaçôes de jogo e da subsequente decisão. As tarefas neste método estimulam nos alunos e/ou atletas o pensamento crítico e a tomada de decisão, processo este de solução de problemas decorrente das experiências já vivenciadas. São apresentadas constelações de jogo com poucos jogadores, semelhante ao jogo na rua, o que permite o aprendizado incidental de regras inerentes ao comportamento tático. Nesta perspectiva, o professor promove um ambiente de aprendizagem que permite aos praticantes compreender o significado das suas ações e assim fomentar a própria capacidade tática e paralelamente o domínio técnico (Greco, 1998; GraÇA, 2007; GraÇA \& Mesquita, 2002; NAscimento \& Barbosa, 2000). Existem características similares entre o método situacional e outras metodologias de ensino com enfoque na tática, sobretudo por fomentarem a autonomia decisional e propiciarem experiências com cunho de motivação na prática dos Jogos Esportivos Coletivos (Greco, 1998; GraçA \& Mesquita, 2002; 2007; Mesquita, Pereira \& GraÇA, 2009). Neste sentido há semelhanças com o Modelo de Educação Desportiva (Siedentop, 1994, 1998), o Modelo Desenvolvimentista (RINK, 1993), o Modelo de Ensino nos Jogos para a Compreensão [Teaching Games for Understanding - TGFU (Thorpe \& Bunker, 1986)], o Modelo de Iniciação Esportiva Universal [IEU (Greco, 1998; Greco \& BENDA, 1998)], o Modelo Escola da Bola [Ballschule (KrÖGER \& Roth, 2002)] e o Modelo de Abordagem Progressiva ao Jogo (Mesquita, GraçA, Gomes \& Cruz, 2005).

Há estudos na literatura que se caracterizam por investigar a influência isolada de cada método de ensino no desenvolvimento do conhecimento tático (GRAÇA \& MEsquita, 2002). Nestes estudos, o espaço temporal das sessões compreende um período inferior, igual ou superior a15 sessões. Nas pesquisas com 15 ou mais sessões foi constatado o desenvolvimento do conhecimento tático (Greco, Memmert \& Morales, 2010; Harrison, Blackemore, Richards, Oliver, Wilkinson \& Fellingham, 2004; Lima, 2008; Martiny \& Gonzáles, 2010; McPherson \& French, 1991; Morales \& Greco, 2007; Pinho, Alves, Greco \& Schild, 2010; Ramos, Nascimento
\& Collet, 2009; Turner \& MartineK, 1995, 1999; VILHENA \& GRECO, 2009). Já nas pesquisas realizadas com uma inferioridade de quinze sessões houve uma heterogeneidade nos resultados, em alguns estudos constatou-se o desenvolvimento do conhecimento tático, em outros não (CORRÊA, Silva \& PAROLI, 2004; Gabriele \& MaXwell, 1995; Griffin, Mitchell \& Oslin, 1995; Stuart \& ThOrpe, 1997; Turner \& MARTINEK, 1992).

É imprescindível que os métodos aplicados pelo treinador ofereçam o progresso das potencialidades e competências do praticante (jogador) (BoJIKIAN, 2002; Silva \& De Rose Junior, 2005; Vilhena \& Greco, 2009). O treinador deve oportunizar a indagação e a compreensão do erro nas decisões táticas e não a punição da falha. Assim, será propiciado ao praticante acesso à construção de respostas embasadas numa interpretação situacional das ações. Isto, pois, as vivências de ensino-aprendizagemtreinamento é que são interpretadas e compreendidas. A falha é algo natural da prática desportiva e o praticante deve possuir liberdade mental para buscar compreender as açôes errôneas (MESQUITA, 2005).

Este estudo justifica-se por ir ao encontro das investigações cientificas da área, ao analisar os métodos de ensino de forma isolada e por uma maior originalidade em investigar de forma combinada. Ressalta-se que o presente estudo não visa uma abordagem dualista entre os métodos investigados e sim uma compilação entre as peculiaridades dos mesmos. KÖNIG, MEMMERT, Nagel, Roth e Zentgraf (2002) e Roth, Kröger e MEMmert (2002) sugerem que a integração da aprendizagem incidental (método de ensino situacional) seguida da intencional (método de ensino tradicional) é a sequência apropriada para o desenvolvimento do conhecimento. Esta sequência foi investigada no presente estudo, para observar a correspondência com a asseveração destes autores. Além disto, GRAÇA e Mesquita (2002) salientam que, recentemente, a investigação passou a dar maior atenção ao conteúdo da tarefa, à sua estruturação pelo professor e às condições de prática, bem como maior relevância aos aspectos cognitivos. Aspectos estes anteriormente negligenciados no ensino e nos estudos científicos.

Constituiu objetivo do presente estudo a investigação das diferenças entre os métodos de ensino situacional e tradicional no desenvolvimento do conhecimento tático declarativo e processual. $\mathrm{Na}$ sequência foi realizada a observação da influência da ordem de aplicação destes métodos no conhecimento tático nas sessôes de ensino-aprendizagemtreinamento no voleibol. 


\section{Métodos}

\section{Amostra}

A amostra deste estudo foi constituída por um total de 36 voluntários $(\mathrm{n}=36)$. A média de idade desses indivíduos corresponde a 13,03 ( \pm 0,74) anos. Participaram desta amostra duas equipes escolares do sexo masculino, tendo uma 12 estudantes/atletas como voluntários para o estudo e a outra 10 . Ambas as equipes começaram o estudo com 20 atletas, mas houveram exclusões causadas pelas faltas dos atletas durante o desenvolvimento do estudo. A faixa etária dos jogadores compreende os 12 e 14 anos de idade.

As equipes disputaram os principais jogos escolares do Estado de Minas Gerais, com participação no módulo principal dos Jogos Escolares de Belo Horizonte e em competições estudantis nacionais relevantes. As equipes pertenciam a diferentes instituições de ensino particular e realizavam os seus treinamentos no horário extraclasse. Estes jogadores escolares possuem no voleibol um tempo de prática médio correspondente a 18,50 meses $( \pm 10,18)$.

Houve a inserção de um grupo controle (GC) composto por estudantes do sexo masculino, com mesma faixa etária dos demais voluntários, matriculados em uma instituição de ensino distinta das outras duas. Os voluntários do GC eram frequentes nas aulas de Educação Física e sem nenhuma participação em treinamentos da modalidade voleibol, dentro ou fora do ambiente escolar. O GC foi composto inicialmente por 20 indivíduos. Este grupo teve exclusóes devido à ausência de alguns indivíduos no momento da coleta de dados. Houve a participação nas fases de avaliação de 14 indivíduos.
$\mathrm{Na}$ realização deste estudo foram respeitadas as normas estabelecidas pelo Conselho Nacional em Saúde, em relação à pesquisa com seres humanos. O mesmo foi aprovado, na Universidade Federal de Minas Gerais, pelo Comitê de Ética em Pesquisa: registro no CAAE 0121.0.203.000-07.

\section{Procedimentos}

Foi designado para cada grupo experimental um processo de ensino-aprendizagem-treinamento diferente na modalidade voleibol. Um grupo (GST) iniciou com o método situacional e depois passou para o método tradicional (método misto: analítico e global) $(\mathrm{n}=12)$. O outro grupo (GTS) começou com o método tradicional e depois passou para o método situacional $(\mathrm{n}=10)$. Cada um dos grupos efetuou ao todo 30 sessóes, sendo 15 em cada um dos métodos de ensino. Foi efetuado um teste de conhecimento tático declarativo e processual, antes e ao fim das 30 sessóes, com a finalidade de se observar os progressos alcançados. Houve aplicação destes mesmos testes ao fim das 15 sessões iniciais de treinamento, antes da transição para aplicação do segundo método de ensino. O estudo seguiu o delineamento exposto no QUADRO 1.

Salienta-se que o GC não realizou nenhum processo de ensino-aprendizagem-treinamento referente ao voleibol. $\mathrm{Na}$ coleta de dados com o GC foi considerado o número de dias que as 15 sessões efetuadas pelos GST e GTS levaram para se concretizar, ou seja, cinco semanas em média. O GC foi inserido no estudo para a confirmação da influência da variável independente (método de ensino) sobre a variável dependente (conhecimento tático).

QUADRO 1- Delineamento experimental.

\begin{tabular}{|c|c|c|c|c|c|c|}
\hline Pré-Teste & \multicolumn{2}{|c|}{$\begin{array}{c}\text { Tratamento } \\
\text { Experimental }\end{array}$} & Pós-Teste 1 & \multicolumn{2}{|c|}{$\begin{array}{c}\text { Tratamento } \\
\text { Experimental }\end{array}$} & Pós-Teste 2 \\
\hline $\begin{array}{l}\text { Conhecimento } \\
\text { Tático Processual: } \\
\text { teste KORA RE } \\
\text { (MEMmERT, 2002); }\end{array}$ & GST & $\begin{array}{c}15 \text { sessôes } \\
\text { de treino } \\
\text { sob o método } \\
\text { situacional }\end{array}$ & $\begin{array}{l}\text { Conhecimento } \\
\text { Tático Processual: } \\
\text { teste KORA RE } \\
\text { (MEMmERT, 2002); }\end{array}$ & GST & $\begin{array}{c}15 \text { sessões } \\
\text { de treino } \\
\text { sob o método } \\
\text { tradicional }\end{array}$ & $\begin{array}{l}\text { Conhecimento } \\
\text { Tático Processual: } \\
\text { teste KORA RE } \\
\text { (MEMMERT, 2002); }\end{array}$ \\
\hline $\begin{array}{l}\text { Conhecimento } \\
\text { Tático Declarativo: } \\
\text { teste de Situações } \\
\text { de Ataque de Rede } \\
\text { no Voleibol } \\
\text { (PAULA, 2000). }\end{array}$ & GTS & $\begin{array}{c}15 \text { sessões } \\
\text { de treino } \\
\text { sob o método } \\
\text { tradicional }\end{array}$ & $\begin{array}{l}\text { Conhecimento } \\
\text { Tático Declarativo: } \\
\text { teste de Situaçóes } \\
\text { de Ataque de Rede } \\
\text { no Voleibol } \\
\text { (PAULA, 2000). }\end{array}$ & GTS & $\begin{array}{c}15 \text { sessões } \\
\text { de treino } \\
\text { sob o método } \\
\text { situacional }\end{array}$ & $\begin{array}{l}\text { Conhecimento } \\
\text { Tático Declarativo: } \\
\text { teste de Situaçóes } \\
\text { de Ataque de Rede } \\
\text { no Voleibol } \\
\text { (PAULA, 2000). }\end{array}$ \\
\hline
\end{tabular}




\section{Instrumento}

Para que o tratamento experimental ocorresse de forma efetiva, os treinadores de ambas as equipes foram instruídos em relação à ordem de aplicação dos métodos de ensino. Além disto, os treinadores foram informados sobre cada método em questão, com auxilio de uma revisão de literatura elaborada pelo pesquisador. No momento em que cada treinador aceitou participar deste estudo, foi direcionado qual o método seria utilizado no primeiro momento e qual a sua sequência. $O$ planejamento e a condução das sessões ficaram a cargo de cada treinador. Eles contemplavam nos treinamentos os conteúdos que consideravam necessários, entretanto, não alteraram o método proposto em cada momento do estudo.

Houve o registro por meio de filmagem de todas as sessões de treinamento, no intuito de confirmação do método de ensino empregado. Posteriormente, foi realizada a categorização destes treinos de acordo com o protocolo formulado por STEFANELLO (1999). NASCIMENTO e BARBOSA (2000) adaptaram este protocolo para o voleibol. Tal protocolo já foi empregado por diferentes estudos no Brasil (Collet, Nascimento, Ramos \& Donegá, 2007; Collet, Nascimento \& Santos, 2008; Costa, Lima, Matias \& Greco, 2007; Donegá, 2007; Morales, 2007; Morales \& Greco 2007; Moreira, 2005; PinHo et al., 2010 ; Ramos, Nascimento \& Collet, 2009; SaAd, 2002; Vilhena, 2007; VILHENA \& GreCO, 2009). Ao efetuar-se a categorização, análise dos tempos destinados as atividades e tarefas desenvolvidas, é possível a confirmação do método de ensino empregado. Neste estudo executouse a categorização dos treinos em duas dimensões: condição da tarefa e complexidade da tarefa.

A análise das condiçôes das tarefas permite determinar seis categorias de conteúdos: a) fundamento individual; b) combinação de fundamentos; c) complexo de jogo 1 (situações que ocorrem o ataque a partir da recepção e levantamento) e complexo de jogo 2 (situaçôes que ocorrem o ataque a partir da defesa ou bloqueio e levantamento); d) jogo formal (competição governada por regras estabelecidas; os resultados são decididos pelas habilidades, estratégias, sendo a exercitação em situação de jogo formal, dentro das regras oficiais); e) jogos para desenvolver a inteligência tática (JDIT) (atividades ou jogos que fazem com que os jogadores tenham que tomar decisões táticas, não sendo essas necessariamente especificas da modalidade); f) estruturas funcionais (situaçôes de jogo com redução do número de jogadores e do espaço, o qual facilita que cada jogador tenha um maior contato com a bola e deva resolver de forma mais frequente situações-problema típicas de jogo, isto com a presença ou não do curinga $(+1)$, por exemplo: $1 \times 1,1 \times 1+1,2 \times 1,2 \times 1+1,2 \times 2,2 \times 2+1$, $3 \times 2,3 \times 2+1,3 \times 3,3 \times 3+1$, etc.).

A categorização da complexidade das tarefas permite a compreensão do modo como o treinador transforma os objetivos e os conteúdos do treino em atividades para os jogadores. Estas atividades se subdividem em: a) aquisição da técnica - elaboração do plano motor (realização da técnica de forma global, que faz com que o indivíduo se preocupe com a execução do movimento); b) fixação da técnica - focaliza aspectos particulares da execução da técnica; c) aplicação da técnica - aplicar as habilidades técnicas em situações que contenham os ingredientes do jogo, mas que facilitam a ocorrência do êxito; d) competição - execução das habilidades técnicas em situações competitivas.

$\mathrm{Na}$ verificação da confiabilidade dos dados da categorização dos treinamentos, realizados por dois profissionais de Educação Física, possuidores do título de treinador expedido pela Federação Mineira de Voleibol, foi utilizado o coeficiente de concordância de Kappa, que retornou uma estatística igual a 1,00 para a variável complexidade da tarefa e 0,98 para condição da tarefa. Como ambos os valores estão muito próximos de 1 e p-valor < 0,001, afirma-se a validade dos dados coletados (Thomas \& Nelson, 2002).

Para avaliar o conhecimento tático processual dos jogadores foi utilizado o teste KORA (Avaliação Orientada através do Conceito dos Peritos), validado por Memmert (2002). Este teste já foi aplicado nos estudos de Moreira (2005), Morales e Greco (2007), Giacomini e Greco (2008), Morales, Greco e Andrade (2009), Vilhena e Greco (2009), Greco, MemmerT e Morales (2010), Pinho et al. (2010), Giacomini, SoAres, Santos, Matias e Greco (2011), entre outros. O teste KORA, utilizado neste estudo, visa medir o conhecimento processual convergente e divergente no parâmetro tático Reconhecer Espaços (RE).

Durante a realização do fundamento ataque no voleibol busca-se reconhecer o espaço livre no sistema defensivo (bloqueio e defesa) do adversário. Ao executar esta ação ofensiva o jogador direciona a bola para um determinado local com a intenção de obter o ponto ou de impedir a construção ofensiva do adversário com todas as possibilidades possíveis no espaço-tempo (Matias, 2009; Matias \& Greco, 2009; PAUla, 2000). A capacidade tática "reconhecer espaços" é observada quando, no conjunto de atividades e jogos, se oportunizam as "tarefas táticas em que 
é importante reconhecer as chances para se chegar ao gol (ponto)" (KRÖGER \& RoTH, 2002, p.32).

No KORA RE há uma pontuação para as ações que o jogador efetua, produto dos conceitos propostos pelos peritos no processo de validação, os quais apresentaram uma consistência interna (Alfa de Cronbach) de 0,98 . Tal valor indica a fidedignidade da avaliação na aplicação do instrumento (MEMMERT, 2002). Houve também o emprego da consistência interna entre os observadores do presente estudo, no voleibol (conhecimento tático produto da combinação de dois diferentes métodos de ensino), isto por meio do coeficiente Alfa de Cronbach. A TABELA 1 mostra os valores obtidos no procedimento de análise de consistência interna entre os avaliadores. Observa-se que os valores de todas as categorias são superiores ao valor mínimo $(0,70)$. Valor este considerado na literatura como aceitável no indicativo da consistência entre os avaliadores (BARROS \& REIS, 2003; PASQUALI, 1996; ThOMAs \& NeLSON, 2002).

TABELA 1 - Valores do coeficienteAlfa deCronbach para confiabilidadeentreavaliadores para o testetático processual.

\begin{tabular}{|c|c|c|}
\hline Fase & Parâmetro tático & Coeficiente \\
\hline Pré-Teste & Processual Re Convergente & 0,92 \\
\hline Pré-Teste & Processual Re Divergente & 0,91 \\
\hline Pós-Teste 1 & Processual Re Convergente & 0,92 \\
\hline Pós-Teste 1 & Processual Re Divergente & 0,87 \\
\hline Pós-Teste 2 & Processual Re Convergente & 0,78 \\
\hline Pós-Teste 2 & Processual Re Divergente & 0,74 \\
\hline
\end{tabular}

Ao realizar o teste KORA, na avaliação do parâmetro tático processual Reconhecer Espaços, os jogadores que compõem as equipes (1) e (3) (FIGURA 1) devem trocar passes dentro da própria equipe com as mãos. Os passes na própria equipe e os direcionados para a outra equipe são efetuados de forma similar ao basquetebol e/ou handebol. Não deve haver preocupação em passar a bola na mão de um membro da outra equipe. A necessidade única é o envio da bola, para o setor da outra equipe, sem que os membros da equipe (2) a intercepte. Os jogadores da equipe (2), por sua vez, devem respeitar a área limitada para sua equipe, ao passo que os sujeitos das equipes (1) e (3) não podem deslocarse quando estão de posse da bola. Os membros das equipes (1) e (3), com tal posse de bola, podem fintar com o corpo e/ou passar a bola para o seu companheiro de equipe, isto até alguém considerar que surgiu o momento propício para passar a bola para a equipe contrária. A altura máxima que a bola pode ultrapassar o espaço defensivo é estabelecida no protocolo do teste: $1,50 \mathrm{~m}$. Esta altura na aplicabilidade do teste corresponde à altura do ombro de cada um dos defensores encarregados pela interceptação dos passes. Sempre que a bola atingir uma altura além do limite descrito a ação tática é invalidada. A bola retornará para o avaliador sempre que um dos membros da equipe (2) interceptar o passe efetuado entre as equipes (1) e (3). O avaliador deve controlar o tempo, a realização correta do teste e a participação de todos os jogadores no teste. 


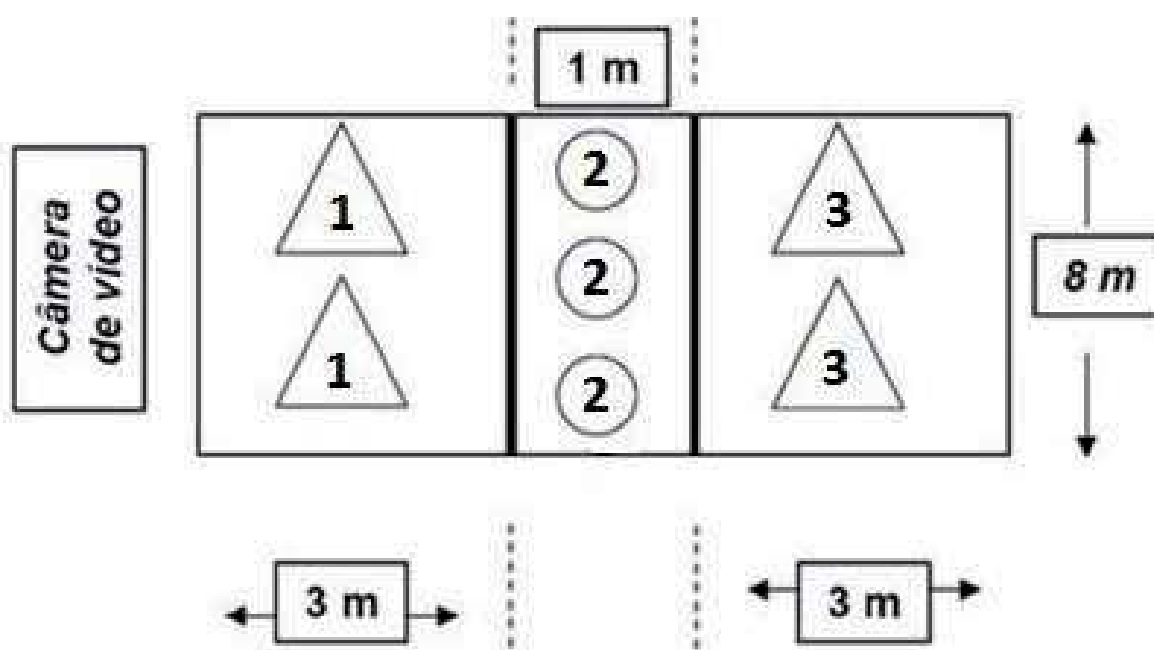

Triângulos: indivíduos que devem trocar passes entre si e/ou passar a bola para os companheiros melhores posicionados na outra equipe;

Círculos: indivíduos que devem interceptar a bola.

FIGURA 1 - Protocolo de avaliação do teste KORA no parâmetro tático processual RE (Reconhecer Espaços) convergente e divergente.

$\mathrm{Na}$ realização do KORA RE, em um espaço de $7 \times 8$ metros e com a duração de dois minutos, os jogadores recebem uma concisa explicação sobre o teste, seus objetivos e as instruções de procedimentos. Depois do esclarecimento das dúvidas os jogadores são encaminhados para o referido teste.

A equipe de posse de bola é divida em duas (dois jogadores para cada lado). Já no setor central se posiciona a equipe responsável por interceptar os passes destinados a outra equipe. Um dos integrantes da equipe de intercepção é retirado do teste, de forma aleatória por seu professor/treinador, sendo então composta por três jogadores posicionados no setor central. Neste teste são avaliados somente os jogadores que integram o "ataque" (equipe com posse de bola). Ao final de dois minutos são realizadas as trocas de função: a equipe do "ataque" passa para a "defesa" (com retirada de um dos integrantes) e a equipe de "defesa" (com o retorno do aluno retirado pelo professor) para o "ataque". Ao término outras duas equipes iniciam o teste.
No KORA RE avalia-se o conhecimento tático processual convergente (inteligência tática) e divergente (criatividade tática). $\mathrm{O}$ processo de avaliação apóia-se no critério estabelecido por MEMMERT (2002), que apresenta uma escala de pontuação que varia entre 0 a 10 pontos. O critério a ser avaliado é a percepção de espaço (reconhecimento de espaço) entre os adversários ao se transpor a bola para a outra equipe: há espaço propício para encaminhar a bola entre os adversários? Está sendo avaliado o jogador que efetua um passe com o objetivo de ultrapassar o setor adversário, sem que um dos defensores intercepte a bola. É analisado o comportamento e as ações do jogador ao efetuar o passe para a outra equipe. Os peritos no teste KORA avaliam o desempenho deste jogador, estabelecem os pontos de acordo com as ações táticas realizadas no quesito Reconhecer Espaços, de acordo com as grelhas de avaliação (QUADROS 2 e 3), por meio da análise das formas subjacentes de pensamento convergente e divergente na ação tática executada. 
LIMA, C.O.V.; MATIAS, C.J .A.S. \& GRECO, P.J .

QUADRO 2 - Grelha de avaliação do teste KORA RE convergente (inteligência tática).

\begin{tabular}{|c|c|c|c|}
\hline $\begin{array}{l}\text { Qualidade da solução } \\
\text { Reconhecer Espaços }\end{array}$ & $\begin{array}{l}\text { Nível de dificuldade } \\
\text { da situação }\end{array}$ & Pontos & Exemplo \\
\hline $\begin{array}{l}\text { Ótimo } \\
\text { Sempre Livre }\end{array}$ & Difícil & 10 & $\begin{array}{l}\text { O jogador enfrenta situações difíceis sempre } \\
\text { utilizando o espaço de forma ótima ou passando a } \\
\text { bola para um colega melhor posicionado. }\end{array}$ \\
\hline $\begin{array}{l}\text { Ótimo } \\
\text { Sempre Livre }\end{array}$ & Fácil & 9 & $\begin{array}{l}\text { O jogador enfrenta somente uma situação de tensão e } \\
\text { utiliza o espaço de forma ótima. Nas outras situações } \\
\text { a dificuldade é média. }\end{array}$ \\
\hline $\begin{array}{l}\text { Muito Bom } \\
\text { Quase Sempre }\end{array}$ & Difícil & 8 & $\begin{array}{l}\text { O jogador utiliza os espaços sempre de maneira adequada, } \\
\text { enfrenta apenas uma situação de grande dificuldade. }\end{array}$ \\
\hline $\begin{array}{l}\text { Muito Bom } \\
\text { Quase Sempre }\end{array}$ & Fácil & 7 & $\begin{array}{l}\text { O jogador utiliza quase sempre o espaço de maneira } \\
\text { ótima, mas enfrenta um defensor mais fraco quando } \\
\text { aparecem as situaçóes. }\end{array}$ \\
\hline \begin{tabular}{|l|} 
Bom \\
Frequentemente
\end{tabular} & Difícil & 6 & $\begin{array}{l}\text { O jogador alterna momentos bons e ruins em seu jogo. } \\
\text { Enfrentou situações fáceis e difíceis alternadamente. }\end{array}$ \\
\hline \begin{tabular}{|l|} 
Suficiente \\
Alternadamente \\
\end{tabular} & Fácil & 5 & $\begin{array}{l}\text { O jogador apresenta várias decisões críticas, mas nenhuma } \\
\text { errada. As situações eram de dificuldade média. }\end{array}$ \\
\hline $\begin{array}{l}\text { Pobre } \\
\text { Quase nunca }\end{array}$ & Difícil & 4 & $\begin{array}{l}\text { O jogador cometeu alguns erros graves em situaçōes } \\
\text { simples, no entanto utiliza os espaços de forma adequada. }\end{array}$ \\
\hline $\begin{array}{l}\text { Pobre } \\
\text { Quase nunca }\end{array}$ & Fácil & 3 & $\begin{array}{l}\text { O jogador apresenta várias decisões erradas, mas não } \\
\text { cometeu erros graves em situaçōes difíceis. }\end{array}$ \\
\hline $\begin{array}{l}\text { Insuficiente } \\
\text { Nunca }\end{array}$ & Difícil & 2 & $\begin{array}{l}\mathrm{O} \text { jogador apresentou várias decisões críticas em } \\
\text { situações que foram consideradas de dificuldade média. }\end{array}$ \\
\hline $\begin{array}{l}\text { Insuficiente } \\
\text { Nunca }\end{array}$ & Fácil & 1 & $\begin{array}{l}\mathrm{O} \text { jogador cometeu muitos e alternados erros em } \\
\text { situaçōes simples. }\end{array}$ \\
\hline
\end{tabular}

QUADRO 3 - Grelha de avaliação do teste KORA RE divergente (criatividade tática).

\begin{tabular}{|c|c|c|c|}
\hline $\begin{array}{c}\text { Originalidade } \\
\text { da Solução na } \\
\text { Situaçáo de jogo } \\
\text { (uso do espaço ou passe) }\end{array}$ & $\begin{array}{l}\text { Flexibilidade nas } \\
\text { Soluçôes das } \\
\text { Situaçôes de jogo }\end{array}$ & Pontos & Exemplo \\
\hline $\begin{array}{l}\text { Amplo acima da média } \\
\text { (muito original) }\end{array}$ & $\begin{array}{c}\text { Duas ou mais ações } \\
\text { originais }\end{array}$ & 10 & $\begin{array}{l}\text { O jogador mostra diferentes soluções originais, pouco } \\
\text { comuns ou pouco conhecidas / esperadas várias vezes. } \\
\text { A descoberta de espaços ou a realização de passes } \\
\text { foram sempre (completamente) excelentes. }\end{array}$ \\
\hline $\begin{array}{l}\text { Amplo acima da média } \\
\text { (original) }\end{array}$ & $\begin{array}{c}\text { Duas ou mais ações } \\
\text { originais }\end{array}$ & 9 & $\begin{array}{l}\text { O jogador mostra diferentes alternativas originais } \\
\text { / fora do comum de solução. A descoberta de } \\
\text { espaços ou a realização de passes foram excelentes. }\end{array}$ \\
\hline $\begin{array}{l}\text { Muito bom } \\
\text { (quase sempre) }\end{array}$ & $\begin{array}{l}\text { Duas ações originais / } \\
\text { que aparecem de forma } \\
\text { pouco frequente }\end{array}$ & 8 & $\begin{array}{l}\text { O jogador mostra diferentes alternativas originais } \\
\text { / fora do comum de solução. A descoberta de } \\
\text { espaços, ou de passes foram pouco frequentes }\end{array}$ \\
\hline $\begin{array}{l}\text { Bom, na média } \\
\text { (algumas vezes) }\end{array}$ & $\begin{array}{l}\text { Duas ações que } \\
\text { aparecem de forma } \\
\text { pouco frequente }\end{array}$ & 7 & $\begin{array}{l}\text { O jogador mostra duas alternativas de soluçôes } \\
\text { diferentes, que não foram pouco comuns, mais } \\
\text { que aparecem na prática com pouca frequência. As } \\
\text { descobertas dos espaços e dos passes foram sempre } \\
\text { cheias de muita surpresa. }\end{array}$ \\
\hline $\begin{array}{l}\text { Na média } \\
\text { (ainda faz coisas novas) }\end{array}$ & $\begin{array}{l}\text { Duas ações pouco } \\
\text { frequentes, novas }\end{array}$ & 6 & $\begin{array}{l}\text { O jogador mostra duas alternativas de soluções diferentes, } \\
\text { que não foram pouco comuns, mais que aparecem } \\
\text { na prática com pouca frequência. As descobertas dos } \\
\text { espaços e de passes foram sempre surpresas. }\end{array}$ \\
\hline
\end{tabular}


QUADRO 3 - Grelha de avaliação do teste KORA RE divergente (criatividade tática) - (continuação).

\begin{tabular}{|c|c|c|c|}
\hline $\begin{array}{c}\text { Originalidade } \\
\text { da Solução na } \\
\text { Situaçáo de jogo } \\
\text { (uso do espaço ou passe) }\end{array}$ & $\begin{array}{l}\text { Flexibilidade nas } \\
\text { Soluçóes das } \\
\text { Situaçôes de jogo }\end{array}$ & Pontos & Exemplo \\
\hline $\begin{array}{l}\text { Suficiente, ainda } \\
\text { (consegue coisas novas) }\end{array}$ & $\begin{array}{l}\text { Uma ação pouco } \\
\text { frequente }\end{array}$ & 5 & $\begin{array}{l}\text { O jogador mostra duas alternativas de solução } \\
\text { diferentes, as mesmas não são do tipo padrão, mais que } \\
\text { apareceram já no jogo. As descobertas dos espaços e dos } \\
\text { passes foram com novidades. }\end{array}$ \\
\hline $\begin{array}{l}\text { Pobre, próximo da média } \\
\text { (com poucas coisas } \\
\text { novas) }\end{array}$ & $\begin{array}{l}\text { Uma ação pouco } \\
\text { frequente }\end{array}$ & 4 & $\begin{array}{l}\text { O jogador mostra duas alternativas de solução } \\
\text { diferentes, as mesmas não são do tipo padrão, mais que } \\
\text { aparecem frequentemente no jogo. As descobertas dos } \\
\text { espaços e dos passes foram com novidades. }\end{array}$ \\
\hline $\begin{array}{l}\text { Pobre } \\
\text { (próximo do padrão) }\end{array}$ & Nenhuma & 3 & $\begin{array}{l}\text { O jogador tem apresentado geralmente soluções padrão, } \\
\text { as que já foram oferecidas. As descobertas dos espaços e } \\
\text { dos passes foram com um pouco de novidade ainda. }\end{array}$ \\
\hline $\begin{array}{l}\text { Insuficiente } \\
\text { (quase somente padrão) }\end{array}$ & Nenhuma & 2 & $\begin{array}{l}\text { O jogador tem apresentado quase sempre soluções } \\
\text { padrão, as que já foram oferecidas. As descobertas dos } \\
\text { espaços e dos passes foram com pouca novidade. }\end{array}$ \\
\hline $\begin{array}{l}\text { Muito Insuficiente } \\
\text { (Somente padrão) }\end{array}$ & Nenhuma & 1 & $\begin{array}{l}\text { O jogador tem apresentado somente soluções } \\
\text { padrão, as que já foram oferecidas. As descobertas } \\
\text { dos espaços e dos passes nunca foram novidade. }\end{array}$ \\
\hline
\end{tabular}

$\mathrm{Na}$ avaliação do conhecimento tático declarativo foi usado o teste validado por PAULA (2000), que engloba situações de ataque na rede no voleibol. As cenas em vídeo do teste são compostas pela sequência: saque, recepção, levantamento, ataque. No momento do ataque a cena é paralisada e desaparece após três segundos. O teste já foi aplicado em diversos estudos (Costa et al., 2007; Greco, Matias, Campos, Souza, Pena, Oliveira, Silva, Gomes, Miranda, Santos, Canabrava, D’Avila \& Ferreira, 2002; Lima, Matias, Greco \& Greco, 2005; Lima, Costa \& Greco, 2011; Matias, Giacomini \& Greco, 2004).

$\mathrm{Na}$ aplicação do teste de conhecimento tático declarativo (PAULA, 2000) cada jogador respondeu 10 situações (tomada de decisão: atacar ou largar? justificativa: o por que desta decisão? justificativa sempre relacionada com o bloqueio e com a defesa adversária). Os jogadores são arguidos em relação à especificidade da função tática de jogo. $\mathrm{O}$ jogador de ponta respondeu situaçóes referentes à sua especificidade no jogo, assim como o jogador central. Isto, pois, nos jogos escolares o sistema tático permitido para esta faixa etária é o $4 \times 2$ ou o $6 \times 6$. As equipes deste estudo empregavam sistema $4 \times 2$. Para a compreensão do teste os voluntários responderam cinco exemplos antes da real aplicação do teste. Os jogadores só foram inquiridos após a compreensão por completo do teste validado por PaUla (2000).

$\mathrm{Na}$ realização do teste de conhecimento tático declarativo foi utilizada, na instituição de ensino de cada uma das equipes, uma sala equipada com um aparelho de DVD e televisão ou computador e projetor de multimídia. Cada jogador possuía lápis, borracha e o formulário desenvolvido especificamente para o teste. $\mathrm{O}$ formulário continha um espaço para o voluntário escolher qual era a melhor opção: bater ou largar. Possuía também um espaço destinado para justificar a respectiva tomada de decisão. Os participantes não tinham pressão de tempo para elaborar as respostas sobre a situação de jogo apresentada.

No teste avalia-se a tomada de decisão e a seguir avalia-se a justificativa, caso a decisão tenha sido correta. A pontuação é assim distribuída: resposta correta para a tomada de decisão: 10 pontos; resposta errada para a tomada de decisão: nenhum ponto; resposta correta da justificativa: de quadro a 10 pontos; resposta errada da justificativa: nenhum ponto; pontuação máxima por questão: 20 pontos; pontuação máxima do teste: 200 pontos. Houve a confirmação da consistência interna entre os avaliadores, em relação ao conhecimento tático declarativo, uma vez que o valor do coeficiente do Alfa de Cronbach no pré-teste, no pós-teste 1 e no pós-teste 2 foi, respectivamente, de 0,99, 1 e 0,99.

\section{Análise estatística}

Para a análise, além da estatística descritiva na categorização dos treinos, empregou-se o Teste de Kruskal Wallis e o Mann Whitney, pois os dados coletados não 
atenderam às condições de normalidade. $\mathrm{O}$ nível de significância adotado foi de $\mathrm{p}<0,05$. O Kruskal Wallis propiciou o exame do estado inicial de cada um dos grupos experimentais (GST, GTS e GC), em relação aos conhecimentos táticos avaliados e o efeito do tratamento experimental ao final das 15 sessões de treino (pós-teste 1 e pós-teste 2). A localização das diferenças entre os

\section{Resultados}

Inicialmente serão apresentados os resultados da categorização dos treinos em duas dimensões: condição da tarefa e complexidade da tarefa. Em seguida os resultados em relação aos conhecimentos decorrentes da aplicação dos métodos de ensinoaprendizagem-treinamento.

Verificou-se que o GST, sob o método situacional, apresentou $425 \mathrm{~min} 61 \mathrm{~s}(44,20 \%)$ em tarefas com uma metodologia apoiada nas estruturas funcionais, $402 \mathrm{~min} 16 \mathrm{~s}(41,77 \%)$ em complexos de jogo 1 e 2 . Os JDIT representaram 7 min $08 \mathrm{~s}$ $(7,38 \%)$ e o complexo de jogo 1 , apenas 11 minutos $(1,14 \%)$. Já o GTS, no momento de ser aplicado o mesmo método, apresentou 544 min 56 s (56,5\%) de atividades apoiadas nas estruturas funcionais e $418 \mathrm{~min} 80 \mathrm{~s}(43,5 \%)$ nas quais se concentram os tipos caracterizados como complexos 1 e 2 .

Na aplicação do método tradicional, verificou-se que o GST realizou fundamentos individuais em 23,47\% do seu tempo total das sessões, o que corresponde a $239 \mathrm{~min}$ 63 s. Além disso, utilizou $324 \mathrm{~min} 76 \mathrm{~s}(25,38 \%) \mathrm{em}$ combinação de fundamentos e $522 \mathrm{~min} 34$ s (51,16\%) do tempo total no nível jogo. Paralelamente, o GTS utilizou $231 \mathrm{~min} 91 \mathrm{~s}(21,13 \%)$ com fundamento individual, 324 min 76 s (29,59\%) com combinaçoes de fundamentos, $41 \mathrm{~min} 25 \mathrm{~s}(3,76 \%)$ com complexos de jogo 1 e 2 e 499 min 80 s (45,53\%) em jogo.

A aplicação da técnica no método situacional em função da solicitação das atividades de jogo realizadas no treinamento foi utilizada em $838 \mathrm{~min}$ 77 s pelo GST $(87,11 \%$ do tempo total usado pelas sessōes de treino) e 963 min 36 s pelo GTS, que utilizou somente essa categoria de exercício.

No GTS não houve o uso dos JDIT, ocorreu a problematização das atividades dentro do próprio voleibol. Assim, quando submetido ao mesmo método situacional, o GTS apresentou 100\% de emprego do tempo para atividades de aplicação da técnica. Já o GST realizou 71 min 08 s de JDIT (7,38\%) como objetivo de utilizar os conhecimentos táticos adquiridos em grupos foi observada por meio do Teste da Mediana (também denominado de Teste Mood ou Teste de Escore Sinalizados). Já com o Mann Whitney foi avaliado o efeito dos treinos, no conhecimento tático, produto das primeiras 15 sessões referentes ao método situacional e tradicional (GST e GTS). O programa utilizado para o tratamento dos dados foi o Minitab (versão 15.1).

outras atividades, muitas vezes de complexidade inferior ao voleibol. O GST, sob o método situacional, realizou 53 minutos $(5,50 \%)$ de tarefas com a função de fixar e diversificar a utilização da técnica. Esta mesma função no método tradicional foi realizada num total de 498 $\min 73$ s $(48,84 \%)$ pelo GST e num total de $495 \mathrm{~min}$ 07 s (45,10\%) pelo GTS. Além disto, os conteúdos relacionados com aquisição da técnica foram realizados pelo GTS em $61 \mathrm{~min} 60 \mathrm{~s}(5,61 \%)$.

Os grupos experimentais que se apoiaram na metodologia com os princípios dos métodos tradicionais (analítico e global) possuíram características de ambos, sendo assim o GST realizou $522 \mathrm{~min} 34 \mathrm{~s}$ $(51,16 \%)$ de jogo formal, enquanto a GTS concluiu $499 \min 80$ s $(45,53 \%)$ e ainda, este grupo utilizou 41 min 25 s de aplicação da técnica (3,76\%).

A partir dos resultados já expostos é confirmada a aplicação do método de ensino situacional e tradicional nos grupos GST e GTS. Serão apresentados, a seguir, os resultados em relação ao conhecimento tático processual e declarativo decorrentes dos métodos de ensino-aprendizagem-treinamento empregados.

Foram comparadas as notas obtidas pelos participantes nos pré-testes dos grupos experimentais no parâmetro conhecimento tático declarativo e processual. Foi possível verificar que os três grupos, com relação aos resultados obtidos nos testes, estavam inicialmente em um mesmo patamar. Esta análise foi realizada por meio do teste de Kruskal Wallis (TABELA 2). Houve evidências estatísticas, ema cada uma das variáveis de conhecimento tático avaliadas, que indicaram que os grupos (GST, GTS e GC) apresentaram resultados similares no pré-teste.

A TABELA 2 permite inferir, que após o tratamento experimental, o conhecimento tático declarativo não apresentou diferença significativa em nenhuma das etapas: Pós-Teste 1 e Pós-Teste 2. Por outro lado, o conhecimento tático processual, tanto convergente quanto divergente, mostrou que pelo menos uma das equipes se difere das demais. A 
localização das diferenças entre os grupos foi observada por meio do Teste da Mediana (FIGURA 2).

$\mathrm{O}$ resultado da FIGURA 2 possibilita inferir que o GST se destacou do GTS por apresentar escores mais elevados no KORA: RE, com exceção no Pós-Teste 2, na avaliação do pensamento divergente, em que seus escores estiveram próximos aos do GTS. Além disso, os resultados dos GTS e GC foram semelhantes em ambas as etapas. Exceto no Pós-Teste 1, do pensamento divergente, cujo valor da mediana do GTS esteve muito próximo do limite inferior do intervalo de confiança do GC, que não tinha experiência prática em voleibol.
Por meio do teste Mann-Whitney (TABELA 3) observa-se que o método situacional aplicado em 15 sessões não produziu efeito significativo no conhecimento tático declarativo $(\mathrm{p}=0,70)$. Entretanto, tal efeito foi significativo em relação ao conhecimento tático processual convergente e divergente. É exposto na FIGURA 2, por intermédio $\mathrm{da}$ inferioridade da mediana do Pré-Teste em relação ao Pós-Teste 1 , o efeito positivo do método situacional no conhecimento tático processual. $\mathrm{O}$ método tradicional não produziu efeito significativo no conhecimento tático (TABELA 3).

TABELA 2 - Resultados do teste de Kruskal Wallis, relativo ao estado inicial eapós a aplicação dos métodos de ensinoaprendizagem-treinamento, paraverificar o conhecimento tático dos grupos experimentais: GST, GTSeGC.

\begin{tabular}{lccc}
\hline & Declarativo & Processual Convergente & Processual Divergente \\
\hline Pré-Teste & & & \\
Chi-Quadrado $\left(\chi^{2}\right)$ & 5,07 & 0,35 & 0,66 \\
Graus de Liberdade & 2 & 2 & 2 \\
P-valor & 0,08 & 0,84 & 0,72 \\
\hline Pós-Teste 1 & 5,28 & 14,17 & 8,43 \\
Chi-Quadrado $\left(\chi^{2}\right)$ & 2 & 2 & 2 \\
Graus de Liberdade & 0,07 & $0,00^{*}$ & $0,01^{*}$ \\
P-valor & 2,04 & & 6,26 \\
Pós-Teste 2 & 2 & 18,54 & 2 \\
Chi-Quadrado $\left(\chi^{2}\right)$ & 0,36 & 2 & $0,04^{*}$ \\
Graus de Liberdade & & $0,00^{*}$ & \\
P-valor & & & \\
\hline
\end{tabular}

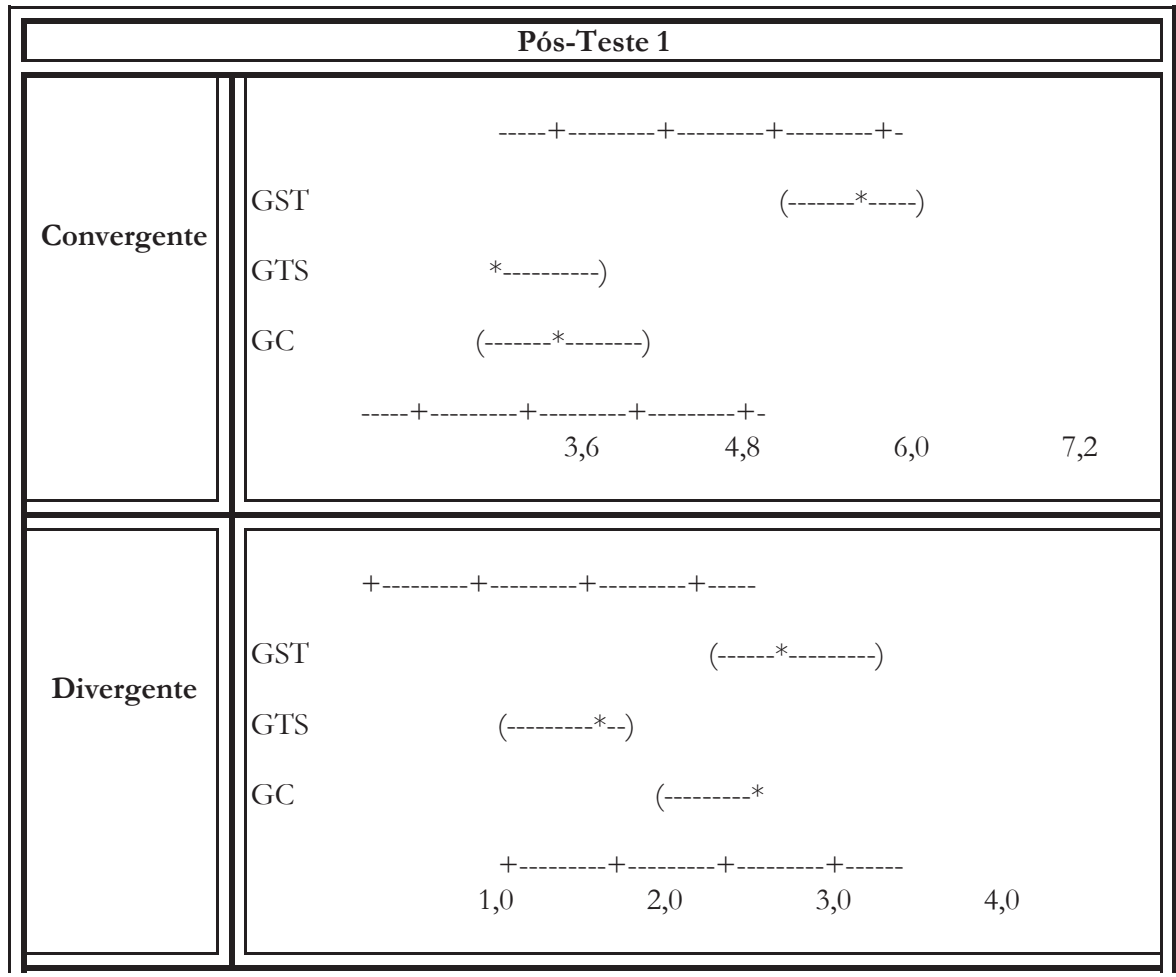

FIGURA 2 - Intervalo de Confiança (95\%) para as medianas do conhecimento tático processual no pós-teste de cada grupo de estudo. 


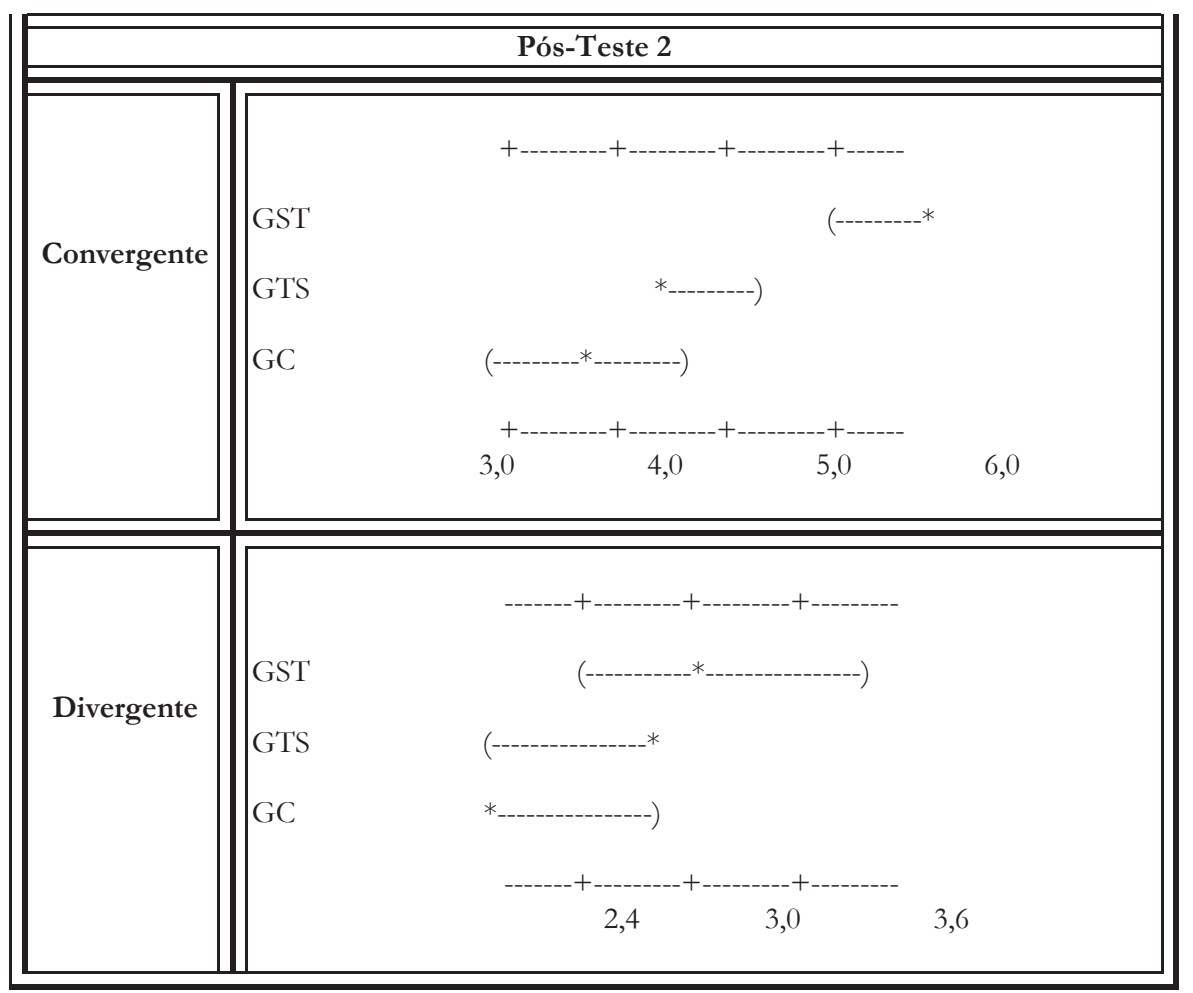

FIGURA 2 - Intervalo de Confiança (95\%) para as medianas do conhecimento tático processual no pós-teste de cada grupo de estudo (Continuação).

TABELA 3 - Teste de Mann Whitney para avaliação do efeito do treinamento aplicado aos grupos GTS e GST nas 15 sessões iniciais de ensino-aprendizagem-treinamento.

\begin{tabular}{llccc}
\hline \multirow{2}{*}{ Tratamento Experimental } & Estatística & \multicolumn{2}{c}{ Conhecimento Tático } \\
\cline { 3 - 4 } & & Declarativo & Processual Convergente & Processual Divergente \\
\hline Método Tradicional & P-valor & 0,65 & 0,93 & 0,59 \\
Método Situacional & P-valor & 0,70 & $0,00^{*}$ & $0,02^{*}$ \\
\hline
\end{tabular}

\section{Discussão}

No tópico Resultados está confirmada a utilização dos métodos propostos no desenho experimental: tradicional e situacional. Abaixo há uma breve argumentação sobre o conceito de tais métodos. Na sequência é apresentada uma discussão à luz dos resultados encontrados: conhecimento tático declarativo e processual.

No método tradicional, o desenvolvimento da capacidade técnica é privilegiado durante o processo, não somente em relação ao volume temporal de atividades, mas também em relação à dedicação nas atividades. Em outras palavras, exercícios em que a repetição é valorizada utilizam o princípio de desenvolvimento dos fundamentos técnicos individuais, ou de combinações destes fundamentos. Já na parte de ensino-aprendizagem-treinamento tático, o jogo formal, no modo do esporte do adulto, é avaliado e apresentado geralmente no final da sessão (COSTA \& NASCimento, 2004; Greco, 2001).

No método situacional desenvolvem-se tarefas que solicitam ao jogador a solução de problemas táticos, a partir das situações típicas do jogo, que determinam um perfil de resposta alcançável pelo jogador. O nível de cobrança tática é determinado pelo treinador bem como pelo ambiente, sendo assim, as atividades que possuem este perfil são classificadas como: estrutura funcional, complexos de jogos e JDIT (NAscimento \& Barbosa, 2000). Além disto, o processo de aprendizado tem como 
característica, no primeiro instante, desenvolver o conhecimento tático. Neste método, a utilização da técnica é entendida principalmente como uma solução dos problemas táticos intrínsecos ao jogo. Objetiva-se com isso, que o atleta, ao escolher e realizar a técnica, o faça em um determinado contexto de jogo, por isso a denominação de situacional. $\mathrm{O}$ conceito apóia-se no desenvolvimento do interesse do atleta em realizar eficientemente o gesto técnico na medida em que a situação de jogo com a qual se defronta assim o solicita (GRECO, 1998, 2001).

Já em relaçao ao JDIT, averigou-se que o GST realizou atividades com o objetivo de utilizar os conhecimentos táticos adquiridos em outros exercícios, muitas vezes de complexidade inferior ao voleibol, pois a aprendizagem implícita (incidental) é superior em situações de baixa complexidade (RAAB, 2003), enquanto que o GTS não realizou. Além disso, o GST realizou tarefas com a função de fixar e diversificar a utilização da técnica, com intuito de fortalecer o plano motor. Desta forma foca-se em aspectos particulares da execução técnica, referenciados aos pontos críticos da realização (NASCIMENTO $\&$ Barbosa, 2000). Na literatura é descrito que na abordagem tradicional o desenvolvimento da técnica precede ao desenvolvimento da tática (HARRISON et al., 2004; Rink, French \& TJeERdsma, 1996; Turner \& MartineK, 1992, 1999). O jogo formal $(6 \times 6)$ é considerado no método global como um momento para motivar o jogador e possibilitar ao próprio o uso do gesto técnico no contexto do jogo (GRECO, 2001).

Em decorrência dos resultados, sugere-se que a sequência de treinamentos aplicados ao GST (método situacional e, em seguida, o método tradicional) tenha ocasionado um melhor desempenho tático processual. Isto, pois, os três grupos estavam num mesmo patamar inicial comprovado pelos resultados dos pré-testes.

Tal achado vai ao encontro das novas abordagens evidenciadas na literatura. Abordagens tais referentes aos métodos de ensino dos Jogos Esportivos Coletivos, centradas no desenvolvimento tático, como o Teaching Games for Understanding (TGFU) e a Escola da Bola (Ballschulle), que propõem uma apropriação do conhecimento tático (declarativo e processual) anterior e/ou em concomitância ao desenvolvimento do gesto técnico (CosTA \& NASCIMENTO, 2004; GRECO, 1998, 2004, 2006a, 2006b; Kröger \& Roth, 2002; Memmert \& Harvey, 2010; Mesquita, 1998, 2005, 2006; Mesquita et al., 2005; RAAB, 2003; Rink, FrenCH \& TJEerdsMA, 1996; Thorpe \& BunKer, 1986). Estes novos métodos, com núcleo na compreensão tática do jogo, propiciam o desenvolvimento dos processos cognitivos para o entendimento do jogo e para respostas adequadas de acordo com o contexto do jogo, além de auxiliar na aquisição de habilidades motoras (Costa \& Nascimento, 2004; Greco, 2004, 2006a, 2006b; Greco \& BendA, 2006). Deste modo, os jogadores assumem um processo mais ativo no processo formativo e são mais competentes na formatação de soluçôes táticas inteligentes e criativas (Costa \& Nascimento, 2004; Nascimento, Ramos, Marcon, SaAd \& Collet, 2009; Vilhena \& Greco, 2009).

Em relação ao conhecimento tático processual, avaliado por meio do teste KORA, o estudo de Moreira (2005) verificou-se que o método global propiciou uma evolução do processual divergente $\mathrm{e}$ convergente no parâmetro oferecer e orientar-se e no reconhecer espaços. Já o método analítico possibilitou o desenvolvimento processual, mas apenas em relação a oferecer e orientar-se. VILHENA e GRECO (2009) verificaram que o emprego do método analítico ocasionou a melhoria do conhecimento tático processual convergente, mas o mesmo não ocorreu em relação ao processual divergente.

Estudos demonstram que o emprego dos métodos com abordagem na compreensão do jogo, nos processos cognitivos que se interagem e produzem decisões táticas no plano motor, tem propiciado melhora significativa no conhecimento tático dos praticantes das diversas modalidades dos Jogos Esportivos Coletivos, em relação aos métodos centralizados no ensino-aprendizagem-treinamento da técnica (Greco, Memmert \& Morales, 2010; GrifFin, Mitchel \& Oslin, 1995; Morales \& Greco, 2007; Morales, Godinho, Matias, Reis \& Greco, 2009b; Ribas, 2010; Turner \& Martinek, 1995, 1999; Vilhena, 2007; Vilhena \& Greco, 2009).

$\mathrm{O}$ não desenvolvimento do conhecimento tático declarativo, por meio de nenhum dos tratamentos experimentais, é um indicativo que este conhecimento pode encontrar-se em procedimentalização. Desta forma, no transcorrer do processo de ensinoaprendizagem-treinamento, houve a mudança de um uso explícito do conhecimento declarativo para o uso implícito do conhecimento processual. A transição do declarativo para o processual é ocasionada por meio do treino e da exercitação (WILliams \& DAVIDS, 1995).

Ao contrário do abordado pelos métodos tradicionais, no processo de ensino-aprendizagem-treinamento, o treinador não deve não ser o foco deste processo. A importância do treinador não é retirada, apenas reconfigurada por meio da observação e pela 
contextualização da instrução nos cenários concretos de prática, com a promoção do desenvolvimento da capacidade de percepção e tomada de decisão do jogador, no ambiente ecológico da tarefa (MESQUITA, 2005; Pereira, Mesquita \& Graça, 2009).

É necessário que as ações tático-técnicas do jogador apresentem uma atitude mais prospectiva do que reativa. $\mathrm{O}$ jogador deve ocupar uma posição central ao ser o construtor ativo das suas próprias aprendizagens. De tal modo, valorizam-se os processos cognitivos, a tomada de decisão e a compreensão da situação-problema (ARAÚJo, 2009; COSTA \& NAScimento, 2004; Greco, 2004; Matias \& Greco, 2010; Mesquita, 2005; Rebello, 2011).

A partir da construção do saber tático, por meio de métodos mais ativos, centrados na tática, o próprio jogador pensará e logo existirá funcionalmente com decisões autônomas dentro da modalidade desportiva coletiva que pratica. Assim, o jogador terá uma maior motivação na prática desportiva. Além disto, estará em interação plena com a configuração ofensiva e defensiva do jogo e em constante evolução no cerne deste contexto, com a produção no espaço-tempo de açôes técnicas fruto de tomadas de decisóes táticas inteligentes e criativas (MESQUITA, 2005; Morales \& Greco, 2007; Vilhena \& Greco, 2009).
O método tradicional poderá se empregado como um aporte integrado aos métodos ativos. Tal aporte contribuirá com aprimoramento da capacidade técnica e, por conseguinte com ações tático-técnicas eficazes em situação real de jogo. Logo, estará contemplado o módulo de ensino-aprendizagem-treinamento que integra em unidade a capacidade de perceber sinais relevantes, a capacidade tática e a capacidade de execução de movimentos. Edificar uma barreira entre a técnica e a tática produz uma falsa lacuna entre as mesmas, dado que ambas são fundamentais para o desempenho no jogo. É necessária a ciência de que a tomada de decisão é limitada e enviesada por constrangimentos de ordem técnica (Coutinho \& Silva, 2009; Gallagher, French, Thomas \& Thomas, 1996; Graça \& Mesquita, 2002, 2007; GRECO, 2001, 2006a, 2006b).

Por fim, existem aspectos referentes à execução das habilidades técnicas (eficiência) que demonstram um maior grau de associação com o resultado atingido (eficácia) relativamente a outros; tal sugere que no processo de ensino-aprendizagemtreinamento é fundamental distinguir o que é mais importante neste processo, na medida em que nem tudo se constitui como fundamento técnico imprescindível para a obtenção do sucesso (MESQUITA, MARQues \& Maia, 2001).

\title{
Conclusões
}

Nenhum dos métodos de ensino empregados de forma isolada (tradicional e situacional) ou combinada (situacional-tradicional e tradicional-situacional) apresentou como resultado, ao fim do processo de ensino-aprendizagem-treinamento, um aumento no conhecimento tático declarativo em situaçôes de ataque de rede no voleibol. A inteligência tática (conhecimento processual convergente) e a criatividade tática (conhecimento processual divergente) apresentaram um desenvolvimento significativo em decorrência da aplicação do método situacional e da combinação da sequência situacional-tradicional no parâmetro reconhecer espaços. Já o método tradicional e a sequência tradiconal-situacional não propiciaram a melhora significativa da inteligência tática e nem da criatividade tática no parâmetro avaliado.

\begin{abstract}
Tactical knowledge as a product of the combination of different teaching methods employed in inversesequences in volleyball

The purpose of this study was to investigate the differences between traditional and situational teaching methods on the acquisition of procedural and declarative tactical knowledge in volleyball sessions of training, and to verify the influence of the order of employment of these methods on tactical knowledge. The sample was composed by 36 students (male/aged 12-14 years), 22 of them were school volleyball players and the other 14 were not volleyball players (control group). One group has started the teaching-learning-training
\end{abstract}


process by using situational method (GST), while in the other group it was used traditional method (GTS). After 15 training sessions, there was an inversion, with the first group using the situational method and the traditional method being applied in the second group during additional 15 training sessions. Training session's categorization (Stefanello, 1999) was conducted in order to confirm the employment of the teaching method. To assess the procedural knowledge was used KORA test (MEMMERT, 2002) on the tactical parameter recognize spaces. For the measurement of declarative tactical knowledge it was utilized the Tactical Knowledge Test of Network Attack Situations (PAULA, 2000). Pre-test scores appointed the three groups to be in similar levels of declarative tactical knowledge, convergent procedural tactical knowledge (tactical intelligence) and divergent procedural tactical knowledge (tactical creativity). On the GST, by applying the situational method (referring to 15 initial sections), there was no significant difference on the tactical declarative knowledge, but there was on the procedure convergent and divergent. On the GTS, by using the traditional method none of the tactical knowledge developed. When making the inversion of learning method on the GST (30 sections on the sequence situational traditional) it was detected a significant improvement of both tactical procedure knowledge. However, this did not occur on the GTS on the traditional-situational sequence. These results suggest that training sequence referring to GST provided significant improvement on the players' tactical intelligence and creativity.

UnITERMS: Cognition and action; Teaching-learning-training; Team games.

\section{Referências}

ANDERSON, J.R. Cognitive psychology and its implications. New York: W.H.Freman, 1995a.

Cognitive psychology and their acquisition. Psychological Review, Washington, v.94, n.1, p.192-210, 1995 b.

ARAÚJO, D. O desenvolvimento da competência táctica no desporto: o papel dos constrangimentos no comportamento decisional. Motriz, Rio Claro, v.15, n.3, p.537-40, 2009.

BANKS, A.P.; MILLWARD, J. Differentiating knowledge in teams: effect of shared declarative and procedural knowledge on team performance. GroupDynamics, Theory, Research, and Practice, Washington, v.11, n.2, p.95-106, 2007.

BARROS, M.V.G.; REIS, R.S. Análise de dados em atividade física e saúde: demonstrando a utilização do SPSS. Londrina: Midiograf, 2003.

BOJIKIAN J.M. Vôlei vs. vôlei. Revista Mackenzie de Educação Física e Esporte, São Paulo, v.1, n.1, p.117-24, 2002. COLLET, C.; NASCIMENTO, J.V.D.; RAMOS, M.H.K.P.; DONEGÁ, A.L. Processo de ensino-aprendizagem-treinamento no voleibol infantil masculino em Santa Catarina. Revista da Educação Física/UEM, Maringá, v.18, n.2, p.147-59, 2007.

COLLET, C.; NASCIMENTO, J.V.D.; SANTOS, T.Z. Processo de treinamento técnico-tático de seleçōes brasileiras de hóquei de grama. Revista Brasileira de Ciência e Movimento, Brasília, v.16, n.2, p.25-32, 2008.

CORRÊA, U.C.; SILVA, A.S.; PAROLI, R. Efeito de diferentes métodos de ensino na aprendizagem do futebol de salão. Motriz, Rio Claro, v.10, n.2, p.79-88, 2004.

COSTA, L.C.A.; NASCIMENTO, J.V.D. O ensino da técnica e da tática: novas abordagens metodológicas. Revista de Educação Física/UEM, Maringá, v.15, n.2, p.49-56, 2004.

COSTA, M.H.C.; LIMA. C.O.V.; MATIAS, C.J.A.S.; GRECO, P.J. Efeito do processo de treinamento técnico-tático no nível de conhecimento declarativo de jovens praticantes de voleibol. Revista Mineira de Educaçáo Física, Viçosa, v.15, n.2, p.5-19, 2007.

COUTINHO, N.F.; SILVA, S.A.P.S. Conhecimento e aplicação de métodos de ensino para os jogos esportivos na formação profissional em educação física. Revista Movimento, Porto Alegre, v.15, n.1, p.117-44, 2009.

DAOLIO, J. Jogos esportivos coletivos: dos princípios operacionais aos gestos técnicos, modelo pendular a partir das idéias de Claude Bayer. Revista Brasileira de Ciência e Movimento, Brasília, v.10, n.4, p.99-104, 2002.

DE ROSE JUNIOR, D.; SILVA, T.A.F. As modalidades esportivas coletivas (MEC): história e caracterização. In: DE ROSE JUNIOR, D. (Ed.). Modalidades esportivas coletivas. Rio de Janeiro: Guanabara Koogan, 2006. p.1-14.

DONEGÁ, A.L. Análise do processo de ensino-aprendizagem-treinamento do voleibol mirim masculino catarinense: um estudo de caso. 2007. 128 f (Dissertação de Mestrado em Teoria e Prática Pedagógica em Educação Física) - Centro de Educação Física e Desporto, Universidade Federal de Santa Catarina, Florianópolis, 2007. 
EYSENCK, M.W.; KEANE, M.T. Psicologia cognitiva: um manual introdutório. Porto Alegre: Artes Médicas, 1994. FRENCH, K.; NEVETT, M.E.; SPURGEON, J.H.; GRAHAM, K.C.; RINK, J.E.; McPHERSON, S.L. Knowledge representation and problem solution in expert and novice youth baseball players. Research Quarterly for Exercise and Sport, Washington, v.67, n.4, p.386-95, 1996.

GABRIELE, T.E.; MAXWELL, T. Direct versus indirect methods of squash instruction. Research Quarterly for Exercise and Sport, Washington, v.66, p.A-63, 1995. Supplement.

GALLAGHER, J.D.; FRENCH, K.E.; THOMAS, K.T.; THOMAS, J.R. Expertise in youth sport: relations between knowledge and skill. In: SMOLL, F.L.; SMITH, R.E. (Eds.). Children and youth sport: a biopsychosocial perspective. Madison: Brown and Benchmark, 1996. p.338-58.

GARGANTA, J. Para uma teoria dos jogos desportivos coletivos. In: GRAÇA, A.; OLIVEIRA, J. (Eds.). O ensino dos jogos desportivos. Porto: Centro de Estudos dos Jogos Desportivos, 1998a. p.11-25.

26, $1998 b$.

O ensino dos jogos desportivos colectivos: perspectivas e tendências. Movimento, Porto Alegre, v.1, n.8, p.19-

.O treino da táctica e da técnica nos jogos esportivos à luz do compromisso cognição-acção. In: BARBANTI, J.; BENTO, J.O.; MARQUES, A.; AMADIO, A. (Eds.). Esporte e atividade física: interação entre rendimento e qualidade de vida. São Paulo: Manole, 2002. p.281-382.

(Re) Fundar os conceitos de estratégia e táctica nos jogos desportivos colectivos, para promover uma eficácia superior. Revista Brasileira de Educação Física e Esporte, São Paulo, v.20, n.5, p.201-3, 2006.

GIACOMINI, S.D.; GRECO, P.J. Comparação do conhecimento tático processual em jogadores de futebol de diferentes categorias e posições. Revista Portuguesa de Ciências do Desporto, Porto, v.8, n.1, p.126-36, 2008.

GIACOMINI, S.D.; SOARES, V.O.; SANTOS, H.F.; MATIAS, C.J.A.S.; GRECO, P.J. O Conhecimento tático declarativo e processual em jogadores de futebol de diferentes escalóes. Motricidade, Vila Real, v.7, n.1. p.43-53, 2011.

GRAÇA, A. Modelos e concepções de ensino do jogo. In: CONGRESSO INTERNACIONAL DE JOGOS DESPORTIVOS-OLHARES E CONTEXTOS DA PERFORMANCE: da iniciação ao rendimento, 1., 2007, Porto. Anais... Porto: Faculdade do Desporto/Universidade do Porto, 2007. p.25-41.

GRAÇA, A.; MESQUITA, I. A investigação sobre o ensino dos jogos desportivos: ensinar e aprender as habilidades básicas do jogo. Revista Portuguesa de Ciências do Desporto, Porto, v.2, n.5, p.67-79, 2002.

A investigação sobre os modelos de ensino dos jogos desportivos. Revista Portuguesa de Ciências do Desporto, Porto, v.7, n.3, p.401-21, 2007.

GRECO, P.J. Cogni(a)cão: conhecimento, processos cognitivos e modelos de ensino-aprendizagem-treinamento para o desenvolvimento da criatividade (tática). Revista Portuguesa de Ciências do Desporto, Porto, v.4, n.2, p.56-9, 2004.

Conhecimento tático-técnico: modelo pendular do comportamento e da ação nos esportes coletivos. Revista

Brasileira de Psicologia do Esporte e do Exercício, Belo Horizonte, v.0, n.1, p.107-29, 2006 .

Conhecimento tático-técnico: eixo pendular da ação tática (criativa) nos jogos esportivos coletivos. Revista Bra-

sileira de Educação Física e Esporte, São Paulo, v.20, n.5, p.210-2, 2006b.

Iniciação esportiva universal: metodologia da iniciação esportiva na escola e no clube. Belo Horizonte: UFMG, 1998. v.2.

Métodos de ensino-aprendizagem-treinamento nos jogos esportivos coletivos. In: GARCIA, E.S.; LEMOS, K.L.M.

(Eds.). Temas atuais VI em educação física e esportes. Belo Horizonte: Health, 2001. p.48-72.

GRECO, P.J.; BENDA, N.R. Iniciação aos esportes coletivos: uma escola da bola para crianças e adolescentes. In: DE ROSE JUNIOR, D. (Ed.). Modalidades esportivas coletivas. Rio de Janeiro: Guanabara Koogan, 2006. p.180-93.

Iniciação esportiva universal: da aprendizagem motora ao treinamento técnico. Belo Horizonte: UFMG. 1998. v.1. GRECO, P.J.; CHAGAS, H.M. Considerações teóricas da tática nos jogos desportivos coletivos. Revista Paulista de Educação Física, São Paulo, v.6, n.2, p.47-58, 1992.

GRECO, P.J.; MATIAS, C.J.A.S.; CAMPOS, P.; SOUZA, P.R.C.; PENA, B.; OLIVEIRA, J.; SILVA, S.A.; GOMES, M.; MIRANDA, G.; SANTOS, M.; CANABRAVA, C.M.; D’AVILA, R.C.C.; FERREIRA, F.E. Análise do nível de conhecimento e rendimento técnico-tático: handebol, futsal e voleibol. In: GARCIA, E.S.; MORAES, L.C. (Eds.). Olimpíada Colegial Jogos da Esperança 2001 - Poços de Caldas, Minas Gerais - Resultado das Avaliações. Belo Horizonte: Centro de Excelência Esportiva/UFMG, 2002. p.121-52.

GRECO, P.J.; MEMERT, D.; MORALES, J.C.P. The effect of deliberate play on tactical performance in basketball. Perceptual and Motor Skills, Missoula, v.110, n.3, p.849-56, 2010.

GRIFFIN, L.L.; MITCHELL, S.A.; OSLIN, J.L. Teaching sport concepts and skills: a tactical approach. Champaign: Human Kinetics, 1995. 
HARRISON, J.M.; BLAKEMORE, C.L.; RICHARDS, R.P.; OLIVER, J.; WILKINSON, C.; FELLINGHAM, G. The effects of two instructional model-tactical and skill teaching-on skill development and game play, knowledge, self-efficacy, and student perceptions in volleyball. Physical Educator, New York, v.61, n.4, p.186-99, 2004.

HENKE, K. A model for memory systems based on processing modes rather than consciousness. Nature Reviews Neuroscience, Cincinnati, v.11, n.7, p.523-32, 2010.

KÖNIG, S.; MEMMERT, D.; NAGEL, Z.; ROTH, K.; ZENTGRAF, K. Spielerisches Taktiklernen: Vom Multitalent zum Spezialisten. In: FERGER, K.; GISSEL, N.; SCHWIER, J. (Eds.). Sportspiele erleben, vermitteln, trainieren. Hamburg: Czwalina, 2002. p.125-46.

KRÖGER, C.; ROTH, K. Escola da bola: um abc para iniciantes nos jogos esportivo. São Paulo: Phorte, 2002.

LIMA, C.O.V. Desenvolvimento do conhecimento tático declarativo e processual no processo de ensino-aprendizagem-treinamento do voleibol escolar. 2008. 166f. Dissertação (Mestrado em Educação Física: Ciências do Esporte) - Escola de Educação Física, Fisioterapia e Terapia Ocupacional, Universidade Federal de Minas Gerais, Belo Horizonte, 2008.

LIMA, C.O.V.; COSTA, H.C.M.; GRECO, P.J. Relação entre o processo de ensino-aprendizagem-treinamento e o desenvolvimento do conhecimento tático no voleibol. Revista Brasileira de Educação Física e Esporte, São Paulo, v.25, n.2, p.251-61, 2011.

LIMA, C.O.V.; MATIAS, C.J.A.S.; GRECO, F.L.; GRECO, P.J. Conhecimento tático declarativo: uma análise no campeonato Brasileiro de Seleções Masculinas Juvenis de Voleibol. Revista Mineira de Educação Física, Viçosa, v.13, n.2, p.135-42, 2005.

MATIAS, C.J.A.S. O conhecimento tático declarativo e a distribuição de jogo do levantador de voleibol: da formação ao alto nível. 2009. 260f. Dissertação (Mestrado em Educação Física: Ciências do Esporte) - Escola de Educação Física, Fisioterapia e Terapia Ocupacional, Universidade Federal de Minas Gerais, Belo Horizonte, 2009.

MATIAS, C.J.A.S.; GIACOMINI, D.S.; GRECO,P.J. Conhecimento tático no voleibol: fator determinante ou não para se estar na seleção brasileira de voleibol. Revista Portuguesa de Ciências do Desporto, Porto, v.4, n.2, p.490, 2004.

MATIAS, C.J.A.S.; GRECO, P.J. Análise de jogo nos esportes coletivos: a exemplo do voleibol. Revista Pensar a Prática, Goiânia, v.12, n.3, p.1-15, 2009.

Cognição e ação nos jogos esportivos coletivos. Ciências \& Cognição, Rio de Janeiro, v.15, n.1, p.252-71, 2010.

MARTINY, L.E.; GONZÁLES, F.J. Os efeitos do processo metodológico para a maximização do tempo de aprendizagem no desenvolvimento de comportamentos técnico-táticos individuais. Revista Brasileira de Ciências e Movimento, Brasília, v.18, n.2, p.35-42, 2010.

McPHERSON, S.L. Tactical differences in problem representations and solutions in collegiate varsity and beginner female tennis players. Research Quarterly and Sport, Washington, v.7, n.4, p.369-84, 1999.

McPHERSON, S.L.; FRENCH, K.E. Changes in cognitive strategies and motor skill in tennis. Journal of Sport and Exercise Psychology, Champaign, v.13, n.1, p.26-41, 1991.

MEMMERT, D. Diagnostik taktischer leistungskomponenten:spieltestsituationen und konzeptorientierte expertenratings (Componentes táticos de diagnósticos de rendimento: teste de situações de jogo e avaliação através do conceito de experts. 2002. Tese (Doutorado em Ciências do Esporte) - Institut für Sport und Sportwissenschaft, Universität de Heidelberg, Heidelberg, 2002.

MEMMERT, D.; HARVEY, S. Identification of non-specific tactical problems in invasion games. Physical Education and Sport Pedagogy, Bedfordshire,v.15, n.3, p.287-305, 2010.

MESQUITA, I. Ensinar bem para aprender melhor o jogo de voleibol. In: TANI, G.; BENTO, J.O.; PETERSEN, R.D.S. (Eds.). Pedagogia do desporto. Rio de Janeiro: Guanabara Koogan, 2006. p.327-44.

O ensino do voleibol: proposta metodológica. In: GRAÇA, A.; OLIVEIRA, J. (Eds.). O ensino dos jogos desportivos. Porto: Faculdade de Ciência do Desporto e de Educação Física/Universidade do Porto, 1998. p.153-200.

. Valorização da aprendizagem autônoma no treino de crianças e jovens. Revista Perfil, Porto Alegre, v.7, n.8, p.15-16, 2005. MESQUITA, I.; GRAÇA, A.; GOMES, A.R.; CRUZ, C. Examining the impact of a step game approach to teaching volleyball on student tactical decision making and skill execution during game play. Journal of Human Movement Studies, New York, v.48, n.6, p.469-92, 2005.

MESQUITA, I.; MARQUES, A.; MAIA, J. A relação entre a eficiência e a eficácia no domínio das habilidades técnicas no voleibol. Revista Portuguesa de Ciências do Desporto, Porto, v.1, n.3, p.33-9, 2001.

MESQUITA, I.M.R.; PEREIRA, F.R.S.; GRAÇA, A.B.S. Modelo de ensino dos jogos desportivos: investigações e ilações para a prática. Motriz, Rio Claro, v.15, n.4, p.944-54, 2009.

MORALES, A.P.; AZEVEDO, M.M.A.; MACIEL, R.N.; BARCELOS, J.C.L.; ÁREAS NETO, N.T.; SILVA, V.F. Eficácia do processamento mental em jogadores de voleibol com níveis metacognitivos diferenciados. Revista da Educaçáo Física/ UEM, Maringá, v.20, n.1, p.43-50, 2009a. 
MORALES, J.C.P. Processo de ensino-aprendizagem-treinamento no basquetebol: influência no conhecimento tático processual. 2007. 176f. (Mestrado em Educação Física: Treinamento Esportivo) - Escola de Educação Física, Fisioterapia e Terapia Ocupacional, Universidade Federal de Minas Gerais, Belo Horizonte, 2007.

MORALES, J.C.P.; GODINHO, E.S.; MATIAS, C.J.A.S.; REIS, A.R.; GRECO, P.J. Processo de ensino-aprendizagemtreinamento no mini-basquetebol. Fitness \& Performance Journal, Rio de Janeiro, v.8, n.5, p.349-59, 2009 b.

MORALES, J.C.P.; GRECO, P.J. A influência de diferentes metodologias de ensino-aprendizagem-treinamento no basquetebol sobre o nível de conhecimento tático processual. Revista Brasileira de Educação Física e Esporte, São Paulo, v.21, n.4, p.291-299, 2007.

MORALES, J.C.P.; GRECO, P.J.; ANDRADE, R.L. A description of the teaching-learning processes in basketball and their effects on procedural tactical knowledge. Revista de Psicologia del Deporte, Palma de Malorca, v.18, p.469-73, 2009. MOREIRA, V.J.P. A influência de processos metodológicos de ensino-aprendizagem-treinamento na aquisição do conhecimento tático no futsal. 2005. 180f. (Mestrado em Educação Física: Treinamento Esportivo) - Escola de Educação Física, Fisioterapia e Terapia Ocupacional, Universidade Federal de Minas Gerais, Belo Horizonte, 2005.

NASCIMENTO, J.V.; BARBOSA, G.B. Estruturação das sessões técnico-táticas no voleibol infanto-juvenil e juvenil feminino: um estudo de caso. In: SIMPÓSIO NACIONAL DE EDUCAÇÃO FÍSICA, 19., 2000, Pelotas. Anais.. Pelotas: Editora Universitária, 2000. p.115-123.

NASCIMENTO, J.V.; RAMOS, V.; MARCON, D.; SAAD, M.A.; COLLET, C. Formação acadêmica e intervenção pedagógica nos esportes. Motriz, Rio Claro, v.15, n.2, p.358-66, 2009.

OLIVEIRA, A.F.; BELTRÃO, B.F.; SILVA, F.V. Metacognição e hemisfericidade em jovens atletas: direcionamento para uma pedagogia de ensino desportivo. Revista Paulista de Educação Física, São Paulo, v.17, n.1, p.5-15, 2003.

PASQUALI, L. Teoria e métodos de medida em ciências do comportamento. Brasília: Laboratório de Pesquisa em Avaliação e Medida da Universidade de Brasília, 1996.

PAULA, A.F.P. Processo de validação de teste para avaliar a capacidade de decisão tática e o conhecimento declarativo no voleibol: situações de ataque de rede. 2000. 215f. (Mestrado em Educação Física: Treinamento Esportivo) - Escola de Educação Física, Fisioterapia e Terapia Ocupacional, Universidade Federal de Minas Gerais, Belo Horizonte, 2000.

PEREIRA, F.; MESQUITA, I.; GRAÇA, A. A autonomia e a responsabilização dos praticantes no treino de voleibol. Estudo comparativo dos treinadores em função do gênero. Revista Portuguesa de Ciências do Desporto, Porto, v.9, n.1, p.64-78, 2009. PINHO, S.T.; ALVES, D.M.; GRECO, P.J.; SCHILD, J.F.G. Método situacional e sua influência no conhecimento tático processual de escolares. Motriz, Rio Claro, v.16, n.3, p.580-90, 2010.

QUEIROGA, M.A. O conhecimento táctico-estratégico do distribuidor de alto nível: um estudo com os distribuidores das seleções brasileiras de voleibol feminino e masculino. 2005. 180f. (Mestrado em Treino de Alto Rendimento) - Faculdade de Ciências do Desporto e de Educação Física, Universidade do Porto, Porto, 2005.

RAAB, M. Decision making in sports: influence of complexity on implicit and explicit learning. International Journal of Sport and Exercise Psychology, Oxford, v.1, p.310-37, 2003.

RAMOS, M.H.K.P.; NASCIMENTO, J.V.; COLLET, C. Avaliação do desenvolvimento das habilidades técnico-táticas em equipes de voleibol infantil masculino. Revista Brasileira de Cineantropometria e Desempenho Humano, Florianópolis, v.11, n.2, p.181-9, 2009.

REBELLO, D.S. Iniciação esportiva: uma abordagem bioética. In: SALLES, A.A. (Ed.). Bioética: velhas barreiras, novas fronteiras. Belo Horizonte: Mazza Edições, 2011. p.257-70.

RIBAS, J.F.M. Praxiologia motriz: instrumentalizando a prática pedagógica para o ensino dos esportes coletivos. Motriz, Rio Claro, v.16, n.1, p.240-250, 2010.

RINK, J.E. Teaching physical education for learning. St. Louis: Mosby, 1993.

RINK, J.E.; FRENCH, K.E.; TJEERDSMA, B.L. Foundations for the learning and instruction of sport and games. Journal of Teaching in Physical Education, Champaign, v.15, n.4, p.399-417, 1996.

RIZOLA, A.N. Uma proposta de preparaçáo para equipes jovens de voleibol feminino. 2003. 135f. (Mestrado em Educação Física: Ciências do Desporto) - Faculdade de Educação Física, Universidade Estadual de Campinas, Campinas, 2003. ROTH, K.; KRÖGER, C.H.; MEMMERT, D. Ballschule Rückschlagspiele. Schorndorf: Hofmann. 2002.

SAAD, M.A. Estruturação das sessões de treinamento técnico-tático nos escalóes de formação do futsal. 2002. 101f. Dissertação (Mestrado em Educação Física: Teoria e Prática Pedagógica em Educação Física) - Centro de Educação Física e Desporto, Universidade Federal de Santa Catarina, Florianópolis, 2002.

SILVA, T.A.F.; DE ROSE JUNIOR, D. Iniciação nas modalidades esportivas coletivas: a importância da dimensão tática. Revista Mackenzie de Educação Física e Esporte, São Paulo, v.4, n.4, p.71-93, 2005. 
SIEDENTOP, D. Aprender a enseñar la educación física. Barcelona: INDE, 1998.

. Sport education: quality PE through positive sport experiences. Champaign: Human Kinetics, 1994.

STERNBERG, R.J. Psicologia cognitiva. 4. ed. Porto Alegre: ArtMed, 2008.

STEFANELLO, J.M.F. A participação da criança no desporto competitivo: uma tentativa de operacionalização e verificação empírica da proposta teórica de Urie Brofenbrenner. 1999. 232f. Tese (Doutorado em Educação Física) - Faculdade de Ciências do Desporto e de Educação Física, Universidade de Coimbra, Coimbra, 1999.

STUART, A.; THORPE, R. A comparison of the effectiveness of two approaches to teaching games within physical education. A skills approach versus a games for understanding approach. The British Journal of Physical Education, London, v.28, n.3, p.9-13, 1997.

THOMAS, J.R.; NELSON, J.K. Métodos de pesquisa em atividade física. 3. ed. Porto Alegre: ArtMed, 2002.

THORPE, R.; BUNKER, D. Landmarks on our way to "teaching for understanding". In: THORPE, R.; BUNKER, D; ALMOND, L. (Eds.). Rethinking games teaching. Loughborough: Leics, 1986. p.5-6.

TURNER, A.P.; MARTINEK, T.J. A comparative analysis of two models for teaching games (technique approach and game-centered (tactical focus) approach). International Journal Physical Education, New York, v.39, n.4, p.15-31, 1992. . An investigation into teaching games for understanding: effects on skill, knowledge, and game play. Research

Quarterly for Exercise and Sport, Washington, v.70, n.3, p.286-96, 1999.

. Teaching for understanding: a model for improving decision making during game play. Quest, Champaign, v.44, n.1, p.44-63, 1995.

VILHENA, M.S. Processo de ensino-aprendizagem-treinamento no futsal: influência no conhecimento tático-processual. 2007. 208f. (Mestrado em Educação Física: Treinamento Esportivo) - Escola de Educação Física, Fisioterapia e Terapia Ocupacional, Universidade Federal de Minas Gerais, Belo Horizonte, 2007.

VILHENA, M.S.; GRECO, P.J. A influência dos métodos de ensino-aprendizagem-treinamento no desenvolvimento da inteligência e criatividade tática em atletas de futsal. Revista Brasileira de Educaçáo Física e Esporte, São Paulo, v.23, n.3, p.297-307, 2009.

WILlIAMS, M. Perceptual and cognitive expertise in sport. The Psychologist, London, v.15, n.8, p.416-7, 2002.

WILLIAMS, M.; DAVIDS, K. Declarative Knowledge in sport: a by-product of experience or a characteristic of expertise. Journal of Sport and Exercise Psychology, Champaign, v.17, n.3, p.259-75, 1995.

ZOUDJI, B.; THON, B.; DEBÛ, B. Efficiency of the mnemonic system of expert soccer players under overload of the working memory in a simulated decision-making task. Psychology of Sport \& Exercise, Amsterdam, v.11, n.1, p.18-26, 2010.

\section{Agradecimentos}

Agradecimento ao apoio da Coordenação de Aperfeiçoamento de Pessoal de Nível Superior (CNPq) e do Conselho Nacional de Desenvolvimento Científico e Tecnológico (Capes), dado para aperfeiçoar a estrutura de pesquisa científica, tecnológica e humana do Centro de Estudos de Cognição e Ação (CECA), da Escola de Educação Física, Fisioterapia e Terapia Ocupacional (Universidade Federal de Minas Gerais).

\begin{tabular}{|c|c|}
\hline $\begin{array}{r}\text { ENDEREÇo } \\
\text { Pablo Juan Greco } \\
\text { Centro de Estudos de Cognição e Ação } \\
\text { scola de Educação Física, Fisioterapia e Terapia Ocupacional } \\
\text { Universidade Federal de Minas Gerais } \\
\text { R. Antônio Carlos, 6627 - Pampulha } \\
\text { 31270-901 - Belo Horizonte - MG - BRASIL } \\
\text { e-mail: grecopj@ufmg.br }\end{array}$ & $\begin{array}{l}\text { Recebido para publicação: 12/ 05/ } 2010 \\
\text { 1a. Revisão: 04/ 01/ } 2011 \\
\text { 2a. Revisão: 30/ 05/2011 } \\
\text { 3a. Revisão: 31/ 10/2011 } \\
\text { Aceito: 23/ 01/2012 }\end{array}$ \\
\hline
\end{tabular}

